\title{
Pengaruh Self Tapping terhadap Penurunan Level Dysmenorhea pada Mahasiswi Program Studi Ilmu Keperawatan
}

\author{
Wiwin Lismidiati, Neni Fidya Santi, Hikmahtika Wulaning Akbar \\ Program Studi Ilmu Keperawatan, Universitas Gajah Mada \\ Email :wiwien_lismidati@ugm.ac.id
}

\begin{abstract}
Abstrak
Dysmenorrhea primer adalah nyeri pada perut bagian bawah yang dirasakan pada saat menstruasi tanpa adanya kelainan pada panggul. Banyaknya gejala yang muncul saat dysmenorrhea dapat berpengaruh pada aktivitas kerja dan aktivitas sehari-hari. Ada beberapa manajemen nyeri untuk mengatasi dysmenorrhea primer, salah satunya adalah dengan self tapping. Tujuan penelitian untuk menganalisis efektifitas terapi self tapping dalam menurunkan level nyeri dysmenorrhea primer pada mahasiswi PSIK FK UGM. Penelitian ini adalah jenis penelitian quasi experiment non randomized pretest-postest with control. Pada kelompok intervensi diberikan perlakuan self tapping, sedangkan pada kelompok kontrol diberikan perlakuan nafas dalam. Pengukuran level nyeri dysmenorrhea primer dilakukan menggunakan instrumen Numerical Rating Scale (NRS) dengan skala 1-10. Jumlah responden sebanyak 60 orang. Untuk mengetahui perbandingan level nyeri sebelum dan sesudah terapi pada kelompok intervensi dan kelompok kontrol, dilakukan uji statistik Wilcoxon. Sedangkan untuk membandingkan perbedaan level nyeri antara kelompok intervensi dan kelompok kontrol dilakukan uji statistik Mann Whitney. Hasil menunjukkan intervensi self tapping lebih efektif menurunkan level nyeri dysmenorrhea primer pada mahasiswi PSIK FK UGM dengan nilai $p=0,007$. Kesimpulannya terdapat pengaruh terapi self tapping terhadap terhadap level nyeri dysmenorrhea primer pada mahasiswi PSIK FK UGM. Terapi self tapping dapat dijadikan pilihan penanganan untuk mengurangi nyeri pada saat mengalami dysmenorrhea primer.
\end{abstract}

Kata kunci: Dysmenorrhea primer, level nyeri, self tapping.

\section{The effect of Self-Tapping on Dysmenorrhea Levels Decrease on Students of Nursing Science Program}

\begin{abstract}
Primary dysmenorrhea is the pain in the lower abdomen that is felt at the time of menstruation without any abnormalities in the pelvis. The number of symptoms that appear when dysmenorrhea occurs can affect daily routine. However, there are some pain management to overcome primary dysmenorrhea, one of which is with selftapping. The purpose of this study was to analyze the effectiveness of self-tapping therapy in decreasing the level of primary dysmenorrhea pain in female students of PSIK FK UGM. This research is a kind of quasi experimental research non randomized pretest-posttest with control. The participants were divided into two groups, they are namely intervention group and control group. In the intervention group, self-tapping treatment was applied to the participants who suffer from dysmenorrhea, whereas deep breathing treatment was applied in the control group. The measurement of primary dysmenorrhea pain level was performed using a 1-10 Numerical Rating Scale (NRS) instrument. The respondents consist of 60 people. In order to figure out the comparison of pain levels before and after therapy in the intervention and control group, the Wilcoxon statistic test was performed. Meanwhile, in comparing the difference of pain level between intervention group and control group, Mann Whitney statistic test was performed. The results showed self-tapping intervention is more effectively decreasing the level of primary dysmenorrhea pain to female students of PSIK FK UGM with $p=0,007$. In conclusion there is a significant influence of self-tapping therapy on the level of primary dysmenorrhea pain applied to female students of PSIK FK UGM. Self-tapping therapy can be a better option to reduce pain when experiencing primary dysmenorrhea.
\end{abstract}

Keywords: Pain level, primary dysmenorrhea, self tapping. 
Wiwin Lismidiati : : Pengaruh Self Tapping terhadap Penurunan Level Dysmenorhea

\section{Pendahuluan}

Dalam tahap perkembangan manusia, setiap manusia pasti mengalami masa remaja atau adolescence. Masa remaja biasanya menunjukkan maturasi dan memasuki masa pubertas yang disertai dengan mengalami menstruasi (Potter \& Perry, 2005). Menstruasi merupakan hal fisiologis pada wanita yang terjadi dari masa menarche sampai menopause. Menstruasi atau haid adalah perdarahan secara periodik dan siklik dari uterus, disertai pelepasan (deskuamasi) endometrium (Proverawati \& Misaroh, 2009).

Hampir seluruh perempuan yang mengalami menstruasi mempunyai pengalaman nyeri haid dengan tingkatan yang berbeda. Mulai dari rasa pegal pada bagian panggul dan perut bagian bawah hingga nyeri yang luar biasa sakitnya. Dalam istilah medis rasa sakit atau nyeri dan kram saat haid disebut dengan dysmenorrhea (Sinsin, 2008). Ada dua jenis dysmenorrhea, yaitu dysmenorrhea primer dan dysmenorrhea sekunder. Apabila rasa sakit yang terjadi karena adanya peradangan panggul, struktur panggul yang tidak normal, pelekatan jaringan pada panggul, endometriosis, tumor, polip, kista ovarium dan penggunaan IUD dinamakan dysmenorrhea sekunder. Tetapi jika rasa sakit yang terjadi tidak disertai dengan adanya riwayat infeksi pada panggul atau panggul dalam keadaan normal dinamakan dysmenorrhea primer.

Diperkirakan angka kejadian dysmenorrhea di Indonesia antara 4595\% di kalangan wanita usia produktif (Proverawati \& Misaroh, 2009). Sumber lain menyebutkan angka kejadian dysmenorrhea di Indonesia sebesar 64,25\% yang terdiri dari 54,89\% dysmenorrhea primer dan 9,36\% dysmenorrhea sekunder. Seringkali dysmenorrhea primer dialami oleh $60-75 \%$ perempuan muda (Hendrik, 2006). Banyaknya gejala yang muncul saat dysmenorrhea dapat berpengaruh pada aktivitas kerja dan aktivitas seharihari (Baradero et al., 2006). Dysmenorrhea primer mengakibatkan penurunan aktivitas, seperti tidak mengikuti pelajaran di sekolah, tidak mengikuti kegiatan, hanya tiduran, dan sulit berjalan (Kusumawati \& Kurniawati,
2011).

Rasa nyeri yang timbul pada saat haid terjadi karena adanya produksi prostaglandin yang berlebihan pada endometrial selama fase luteal. Prostaglandin berdifusi ke dalam endometrial dan menyebabkan kontraksi rahim (Corwin, 2009). Salah satu penanganan nonfarmakologi yang dapat mengurangi nyeri adalah terapi self tapping.

Self tapping adalah tapping touch yang dilakukan secara mandiri. Tapping touch adalah sebuah teknik perawatan secara menyeluruh yang menggunakan sentuhan dan irama. Pijatan lembut membantu untuk mengurangi ketegangan dalam tubuh dan pikiran serta untuk meningkatkan suatu perasaan sejahtera dan pemikiran positif. Self tapping merupakan terapi sederhana yang mudah dilakukan oleh siapapun, dapat dilakukan sendiri dan tidak memerlukan biaya yang banyak (The Association of Tapping Touch, 2010).

Hasil studi pendahuluan yang telah dilakukan pada remaja puteri di Program Studi Ilmu Keperawatan Fakultas Kedokteran UGM, menunjukkan bahwa angka dysmenorrhea masih cukup tinggi. Dari 188 mahasiswi, mahasiswi yang mengalami dysmenorrhea sebanyak 134 orang. Selain itu, hampir semua mahasiswi belum mengetahui mengenai terapi self tapping saat mengalami dysmenorrhea. Berdasarkan hasil studi pendahuluan tersebut, peneliti tertarik untuk melakukan penelitian ini di Program Studi Ilmu Keperawatan Fakultas Kedokteran UGM. Tujuan penelitian ini adalah untuk mengidentifikasi efektifitas terapi self tapping dalam menurunkan level nyeri dysmenorrhea primer pada mahasiswi PSIK FK UGM.

\section{Metode Penelitian}

Penelitian ini adalah jenis penelitian quasi eksperimental dengan rancangan non equivalent pre-test-post-test with control group. Pada penelitian ini terdapat satu kelompok responden yang diberikan perlakuan atau kelompok intervensi dan satu kelompok responden yang diberikan perlakuan lain atau kelompok kontrol. Pada kelompok intervensi, responden diberikan 
terapi self tapping. Pengukuran nyeri dilakukan sebanyak dua kali, yaitu sebelum dan sesudah diberikan perlakuan. Responden diberikan intervensi atau perlakuan selama 15 menit ketika responden mengeluhkan adanya nyeri haid. Pemijatan atau self tapping dilakukan dengan intensitas pijatan yang sama yaitu pada intensitas sedang. Sedangkan pada kelompok kontrol, responden diberikan perlakuan teknik relaksasi nafas dalam sebanyak 15 kali. Pengukuran nyeri dilakukan sebelum dan sesudah responden melakukan nafas dalam, serta tidak dilakukan training untuk dapat melakukan self tapping.

Panduan self tapping didapatkan dari The Assosiation of Tapping Touch berupa langkah langkah tapping yang dilakukan secara mandiri dan disertai dengan gambar. Panduan tersebut selanjutnya dikemas dalam bentuk booklet yang dilengkapi dengan panduan pelaksanaan penelitian yang dibawa oleh responden. Kemudian responden melakukan secara mandiri langkah langkah dari self tapping yang telah disusun didalam booklet bagi kelompok intervensi. Hal yang sama juga diberikan pada kelompok kontrol dengan booklet berisi panduan pelaksanaan relaksasi nafas dalam.

Penelitian ini dilakukan di ruang skills lab Program Studi Ilmu Keperawatan Fakultas Kedokteran UGM Yogyakarta saat responden mengalami dysmenorrhea primer di area kampus dan ketika tidak memungkinkan, penelitian dilakukan di tempat tinggal masing-masing responden. Waktu penelitian dilaksananakan pada bulan Juli hingga Agustus 2015.

Populasi pada penelitian ini adalah mahasiswi Program Studi Ilmu Keperawatan

Fakultas Kedokteran UGM Yogyakarta yang berusia 19-22 tahun. Penentuan jumlah sampel dalam penelitian ini menggunakan teknik sampel minimal. Menurut Sugiyono (2007) jumlah sampel dalam penelitian minimal adalah 30 orang. Sehingga dalam penelitian ini jumlah sampel keseluruhan sebanyak 60 orang, dengan 30 orang sebagai kelompok intervensi dan 30 orang sebagai kelompok kontrol. Sedangkan penentuan 60 orang sampel ini menggunakan teknik random allocation sampling.

Penelitian ini menggunakan lembar kuesioner karekteristik responden, angket skrining dysmenorrhea, lembar prosedur penelitian, dan lembar checklist tahapan pengukuran nyeri dan terapi. Angket skrining dysmenorrhea dilakukan untuk melakukan skrining mahasiswi PSIK FK UGM yang sesuai dengan kriteria inklusi dan tidak sesuai dengan kriteria eksklusi. Sedangkan lembar checklist digunakan untuk memastikan responden melakukan pengukuran nyeri dan terapi dengan benar. Pengumpulan data dilakukan satu kali dari siklus menstruasi responden. Data nyeri sebelum perlakuan didapatkan sebelum intervensi, kemudian intervensi diberikan yaitu self tapping pada kelompok intervensi dan teknik relaksasi nafas dalam pada kelompok kontrol. Setelah selesai, kurang lebih dengan durasi 30 menit, responden diukur kembali untuk data posttest. Instrumen penelitian untuk mengukur nyeri menggunakan NRS (Numerical Rating Scale). Pengukuran nyeri dan terapi dilakukan sendiri oleh responden (self report).

\section{Hasil Penelitian}

Tabel 1 Karakteristik Responden pada Kelompok Intervensi dan Kontrol ( $\mathbf{N = 6 0 )}$

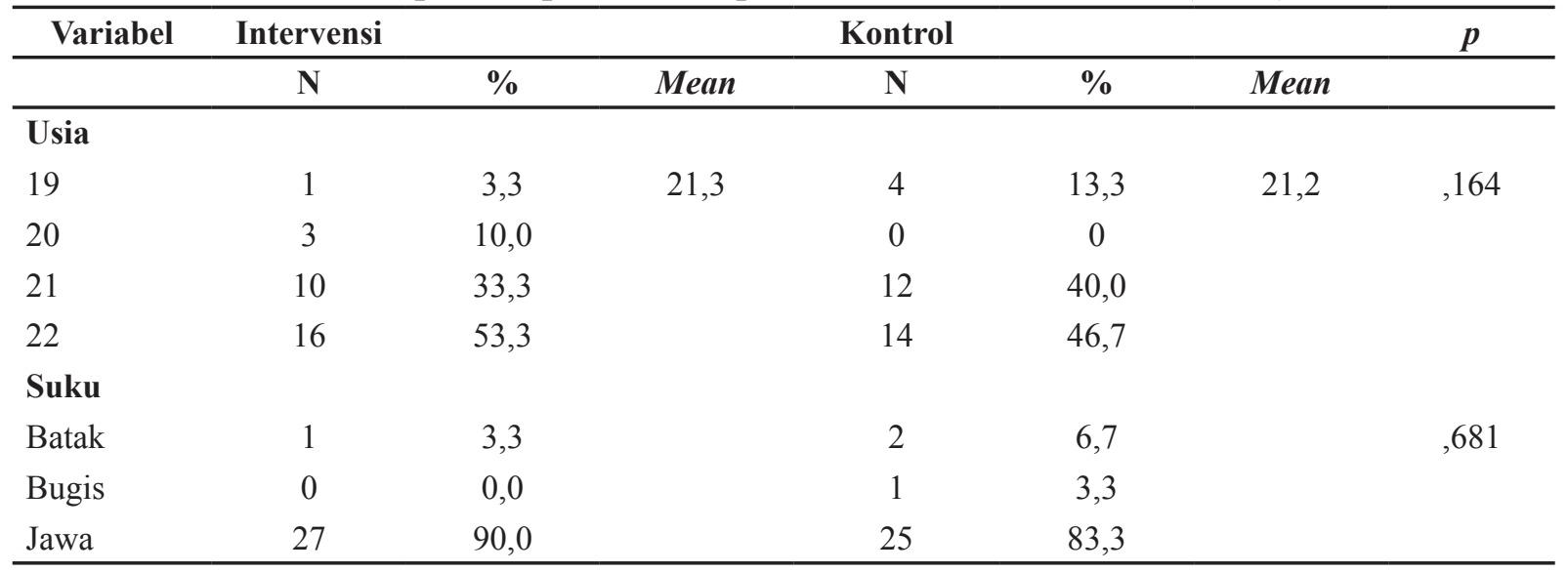

JKP - Volume 5 Nomor 1 April 2017 
Wiwin Lismidiati : : Pengaruh Self Tapping terhadap Penurunan Level Dysmenorhea

\begin{tabular}{|c|c|c|c|c|c|c|c|}
\hline Variabel & Intervensi & & & Kontro & & & $p$ \\
\hline & $\mathbf{N}$ & $\%$ & Mean & $\mathbf{N}$ & $\%$ & Mean & \\
\hline Rote & 1 & 3,3 & & 0 & 0,0 & & \\
\hline Sunda & 1 & 3,3 & & 2 & 6,7 & & \\
\hline \multicolumn{8}{|l|}{ Status gizi } \\
\hline Kurus & 5 & 16,7 & & 10 & 15,0 & &, 320 \\
\hline Normal & 23 & 76,7 & & 18 & 41,0 & & \\
\hline Gemuk & 2 & 6,7 & & 2 & 4,0 & & \\
\hline \multicolumn{8}{|l|}{ Usia menarche } \\
\hline 10 & 0 & 0,0 & 12,3 & 1 & 3,3 & 12,3 & ,827 \\
\hline 11 & 6 & 20,0 & & 5 & 16,7 & & \\
\hline 12 & 11 & 36,7 & & 12 & 40,0 & & \\
\hline 13 & 10 & 33,3 & & 8 & 26,7 & & \\
\hline 14 & 3 & 10,0 & & 4 & 13,3 & & \\
\hline \multicolumn{8}{|l|}{$\begin{array}{l}\text { Penanganan } \\
\text { nyeri }\end{array}$} \\
\hline Istirahat & 22 & 73,3 & & 27 & 90,0 & & , 185 \\
\hline Farmakologi & 7 & 10,0 & & 2 & 6,7 & & \\
\hline $\begin{array}{l}\text { Non } \\
\text { Farmakologi }\end{array}$ & 5 & 16,7 & & 1 & 3,3 & & \\
\hline \multicolumn{8}{|c|}{ Tempat tinggal } \\
\hline Kos & 24 & 80,0 & & 20 & 66,7 & & ,191 \\
\hline Rumah & 6 & 20,0 & & 10 & 33,3 & & \\
\hline \multicolumn{8}{|l|}{$\begin{array}{l}\text { Lama } \\
\text { menstruasi }\end{array}$} \\
\hline$<7$ hari & 22 & 73,3 & & 26 & 86,7 & & ,167 \\
\hline$>7$ hari & 8 & 26,7 & & 4 & 13,3 & & \\
\hline \multicolumn{8}{|l|}{$\begin{array}{l}\text { Kejadian nyeri } \\
\text { menstruasi }\end{array}$} \\
\hline $\begin{array}{l}\text { Berubah- } \\
\text { ubah }\end{array}$ & 1 & 3,3 & & 2 & 6,7 & & ,412 \\
\hline $\mathrm{H}-3$ & 0 & 0,0 & & 2 & 6,7 & & \\
\hline $\mathrm{H}-1$ & 4 & 13,3 & & 6 & 20,0 & & \\
\hline H1 & 22 & 73,3 & & 19 & 63,3 & & \\
\hline $\mathrm{H} 2$ & 3 & 10,0 & & 1 & 3,3 & & \\
\hline \multicolumn{8}{|l|}{ Lama nyeri } \\
\hline $1-2 \mathrm{jam}$ & 4 & 13,3 & & 2 & 66,7 & & ,147 \\
\hline 2-3 jam & 5 & 16,7 & & 7 & 23,3 & & \\
\hline$>3 \mathrm{jam}$ & 21 & 70,0 & & 21 & 70,0 & & \\
\hline \multicolumn{8}{|l|}{$\begin{array}{l}\text { Keteraturan } \\
\text { menstruasi }\end{array}$} \\
\hline Teratur & 27 & 90,0 & & 28 & 93,3 & & ,643 \\
\hline Tidak teratur & 3 & 10,0 & & 2 & 6,7 & & \\
\hline
\end{tabular}


Wiwin Lismidiati : : Pengaruh Self Tapping terhadap Penurunan Level Dysmenorhea

\begin{tabular}{|c|c|c|c|c|c|c|c|}
\hline Variabel & Intervensi & & & Kontrol & & & $p$ \\
\hline & $\mathbf{N}$ & $\%$ & Mean & $\mathbf{N}$ & $\%$ & Mean & \\
\hline \multicolumn{8}{|l|}{$\begin{array}{l}\text { Nyeri sebelum } \\
\text { terapi }\end{array}$} \\
\hline Tidak ada nyeri & 0 & 0,0 & 5,30 & 0 & 0,0 & 5,13 & ,586 \\
\hline Ringan & 0 & 0,0 & & 1 & 3,3 & & \\
\hline Sedang & 27 & 90,0 & & 25 & 83,3 & & \\
\hline Berat & 3 & 10,0 & & 4 & 13,3 & & \\
\hline Sangat berat & 0 & 0,0 & & 0 & 0,0 & & \\
\hline
\end{tabular}

Tabel 2 Perbandingan Skor Nyeri sebelum dan sesudah Pemberian Perlakuan pada Kelompok Intervensi dan Kontrol $(\mathrm{N}=60)$

\begin{tabular}{cccccccc}
\hline & \multicolumn{3}{c}{ Intervensi $(\mathbf{n}=\mathbf{3 0})$} & \multicolumn{3}{c}{ Kontrol $(\mathbf{n}=\mathbf{3 0})$} & \multicolumn{1}{c}{ mean } \\
\hline & Mean & Min & Max & Mean & Min & Max & \\
\hline Sebelum & 5,30 & 4 & 8 & 5,13 & 3 & 7 & 0,17 \\
Sesudah & 4,17 & 2 & 8 & 4,73 & 2 & 7 & $-0,56$ \\
Smean & 1,13 & & & 0,40 & & & 0,73 \\
Nilai p & 0,001 & & & 0,134 & & & 0,007 \\
\hline
\end{tabular}

Sumber : Data primer, 2015

Karekteristik responden meliputi usia, suku, status gizi, usia menarche, penanganan nyeri yang dilakukan sebelumnya, tempat tinggal, lama menstruasi, hari kejadian menstruasi, lama nyeri, keteraturan menstruasi, dan riwayat gangguan menstruasi. Berikut ini tabel mengenai persebaran karakteristik responden (Tabel 1).

Tabel 1 diketahui tidak ada perbedaan yang signifikan karekteristik responden baik pada kelompok intervensi dan kelompok kontrol dengan nilai $p>0,05$. Dengan demikian karekteristik responden dapat dikatakan homogen.

Hasil uji Wilcoxon menunjukkan bahwa terdapat perbedaan yang signifikan untuk skor nyeri sebelum dan setelah self tapping dengan nilai $p<0,01$ Sedangkan pada kelompok kontrol diketahui bahwa tidak terdapat perbedaan yang signifikan untuk skor nyeri sebelum dan setelah nafas dalam dengan nilai $p>0,01$ yaitu 0,134 . Untuk membandingkan penurunan nyeri pada kelompok intervensi dan kelompok kontrol, dilakukan uji Mann Whitney. Hasilnya menunjukkan bahwa intervensi self tapping lebih efektif menurunkan level nyeri dysmenorrhea primer pada mahasiswi PSIK FK UGM dengan nilai $p<0,01$.

\section{Pembahasan}

Kelompok intervensi pada penelitian ini diberikan perlakuan terapi self tapping. Pelaksanaan terapi dilakukan dengan durasi selama 15 menit dengan intesitas dan kekuatan totok sedang menurut masingmasing responden. Hasilnya menunjukkan adanya perbedaan yang signifikan pada rerata skor nyeri sebelum dan sesudah terapi.

Secara fisiologis self tapping dapat menghilangkan ketegangan fisik, memberikan perasaan nyaman dan energi yang baru, pengurangan nyeri fisik dan kelelahan, pengurangan gejala stres fisik, adanya aktivasi sistem saraf parasimpatis, dan adanya peningkatan hormon serotonin (The Association of Tapping Touch, 2010). Penelitian terkini yang dilakukan di Toho University Jepang mengenai pengaruh terapi tapping terhadap hormon serotonin menunjukkan hasil terapi tapping dapat meningkatkan hormon serotonin. 
Wiwin Lismidiati : : Pengaruh Self Tapping terhadap Penurunan Level Dysmenorhea

Serotonergik (5-HT) neuron diketahui berperan dalam menghilangkan kecemasan, nyeri, ketegangan dan gejala depresi pada manusia (Madjid, 2011)

Serotonergik (5-HT) diketahui memiliki peran yang penting dalam penurunan level kecemasan, ketegangan, nyeri, dan gejala depresi diantara manusia. Sekresi serotonin dapat ditingkatkan oleh aktivitas yang berirama seperti bejalan, berenang, mengunyah,dll (Muller et al., 2010). Self tapping atau tapping touch merupakan terapi yang melibatkan perilaku berirama, yaitu dengan melakukan sentuhan secara berirama menggunakan bantalan jari-jari tangan kanan dan kiri secara bergantian. Adanya gerakan yang berirama ini menyebabkan peningkatan sekresi serotonin.

Dalam penelitian yang dilakukan oleh Arita di Departemen Medis Toho University, membuktikan adanya kadar serotonin yang meningkat pada responden yang melakukan tapping touch. Terdapat sembilan responden yang berumur 18-76 tahun. Responden diminta untuk melakukan tapping touch secara berpasangan selama 15 menit. Untuk menilai aktivitas serotonergik, dilakukan pemeriksaan kadar serotonin pada darah dan urin sebelum dan sesudah melakukan terapi. Hasilnya didapatkan bahwa terdapat peningkatan kadar serotonin yang signifikan antara sebelum dan sesudah terapi. Selain itu, untuk menilai efek psikologis dilakukan pengukuran dengan parameter Profile of Mood States (POMS) dan Visual Analog Scale (VAS). Hasilnya menunjukkan bahwa terjadi pengurangan kecemasan, kelelahan, kebingungan, stres, dan nyeri (The Association of Tapping Touch, 2010).

Pengambilan data, baik pada kelompok intervensi dan kelompok kontrol, dilakukan sendiri oleh responden (self report) menggunakan booklet yang sudah diberikan. Peneliti tidak dapat melihat secara langsung proses pelaksanaan terapi dan pengukuran nyeri, sehingga peneliti tidak dapat memastikan langkah-langkah terapi dilakukan dengan benar oleh responden. Selain itu, peneliti juga tidak dapat memastikan keadaan lingkungan tar klien sehingga hal ini dapat mempengaruhi nyeri klien.

Terdapat dua orang responden dari kelompok intervensi dan tiga orang dari kelompok kontrol yang melakukan terapi dan pengukuran nyeri di skills lab. Sedangkan sisanya (28 orang kelompok intervensi dan 27 orang kelompok kontrol) melakukan di dalam ruang skills lab yang terdapat pendingin ruangan, sehingga faktor suhu dapat dikontrol. Tetapi peneliti tidak dapat memastikan kenyamanan yang lain seperti adanya orang yang berlalu lalang dan tingkat kebisingaan.

Selain itu, tahapan terapi dan pengukuran nyeri dapat dilihat dari lembar checklist. Terdapat dua orang responden $(6,6 \%)$ dari kelompok intervensi yang tidak melakukan terapi self tapping selama 15 menit. Dari dua orang responden yang tidak melakukan terapi selama 15 menit tersebut, terdapat satu orang menunjukkan hasil pengukuran skor nyeri yang meningkat. Sedangkan satu orang lainnya menunjukkan hasil adanya penurunan skor nyeri. Sedangkan pada kelompok kontrol terdapat satu orang responden $(3,3 \%)$ yang tidak mempersiapkan lingkungan yang nyaman sebelum terapi dan tidak melakukan nafas dalam selama 15 kali hembusan nafas. Hasil pengukuran nyeri pada responden tersebut mengalami penurunan level nyeri sebanyak satu tingkat.

Kelompok kontrol dalam penelitian ini diberikan perlakuan berupa terapi relaksasi nafas dalam. Menurut Huges et al. (2005) teknik relaksasi melalui olah nafas merupakan salah satu keadaan yang mampu merangsang tubuh untuk membentuk sistem penekan nyeri yang akhirnya menyebabkan penurunan nyeri, disamping itu juga bermanfaat untuk pengobatan penyakit dari dalam tubuh meningkatkan kemampuan fisik dan keseimbangan tubuh dan pikiran, karena olah nafas dianggap membuat tubuh menjadi rileks sehingga berdampak pada keseimbangan tubuh dan pengontrolan tekanan darah.

Pada kelompok kontrol terdapat dua orang responden yang kehilangan booklet yang sudah diberikan. Sehingga pengukuran nyeri dan terapi harus dilakukan kembali pada siklus menstruasi berikutnya. Kedua orang responden tersebut melakukan pengukuran dan terapi kembali pada hari menstruasi yang sama dengan saat melakukan pengukuran 
nyeri dan terapi yang pertama, yaitu pada hari pertama menstruasi. Adanya pengulangan pengambilan data ini, dikhawatirkan menimbulkan perbedaan hasil pengukuran pada pengambilan data pertama dan kedua.

Pada penelitian ini didapatkan hasil bahwa setelah dilakukan teknik relaksasi nafas dalam rata-rata skor nyeri mengalami penurunan. Tetapi setelah diuji menggunakan uji Wilcoxon, hasilnya menujukkan tidak ada pengaruh teknik relaksasi nafas dalam terhadap penurunan nyeri dysmenorrhea primer.

Adanya perbedaan yang signifikan antara rata-rata skor nyeri sebelum dan sesudah terapi pada kelompok kontrol dapat terjadi karena durasi terapi yang hanya sebentar. Pelaksanaan nafas dalam sebanyak 15 kali hembusan nafas dengan istirahat singkat setelah tiga kali hembusan hanya membutuhkan waktu kurang lebih tiga menit. Hal ini sangat berbeda dengan durasi terapi pada kelompok intervensi. Pada penelitian yang dilakukan oleh Azizah (2014) nafas dalam dilakukan secara berulang selama 10 menit, sehingga dapat menurunkan skala nyeri dysmenorrhea primer pada remaja.

\section{Simpulan}

Hasil penelitian tentang pengaruh self tapping terhadap intensitas nyeri dysmenorrhea primer pada mahasiswi PSIK FK UGM dapat disimpulkan bahwa terdapat pengaruh terapi self tapping terhadap level nyeri dysmenorrhea primer pada mahasiswi PSIK FK UGM dengan nilai $p=0,007$, ratarata level nyeri dysmenorrhea primer pada kelompok kontrol sebelum melakukan nafas dalam adalah 5,13 dan sesudah melakukan nafas dalam adalah 4,73, tidak terdapat perbedaan yang signifikan dengan nilai $p=$ 0,134 , rata-rata level nyeri dysmenorrhea primer pada kelompok intervensi sebelum melakukan self tapping adalah 5,30 dan sesudah melakukan self tapping adalah 4,17 terdapat perbedaan yang signifikan dengan nilai $p=0,001$.

Meskipun masih ditemukan beberapa kelemahan dalam pelaksanaan penelitian, namun self tapping merupakan pilihan penenganan yang dapat diaplikasikan secara mandiri dalam penanganan dysmenorrhea primer, dengan tetap memerhatikan pelaksanaan sesuai panduan maupun lingkungan sekitar yang memengaruhi kenyamanan.

Bagi peneliti selanjutnya dapat mengembangkan terapi self tapping ini dengan memerhatikan pengukuran level nyeri dysmenorrhea primer yang dapat dilakukan lebih dari satu kali siklus menstruasi sehinnga dapat digunakan sebagai pembanding. Pengukuran level nyeri tidak hanya dilakukan dengan self report, tetapi juga dengan observasi peneliti sehingga dapat mengamati jalannya penelitian dan dapat mengamati atau mengontrol faktor yang menyebabkan bias hasil penelitian. Intensitas dan kekuatan ketukan yang dilakukan pada terapi self tapping disamakan secara objektif seperti penggunaan alat bantu tertentu.

\section{Daftar Pustaka}

Azizah, N. (2014). Aplikasi relaksasi nafas dalam sebagai upaya penurunan skala nyeri menstruasi (dismenore) pada siswi MTS Ibtidaulfalah Samirejo Dawe Kudus tahun 2013. Jurnal Ilmu Keperawatan dan Kebidanan, 5(1), 14-22.

Baradero, M., Marry, W.D., \& Yakobus, S. (2006). Seri asuhan keperawatan klien gangguan reproduksi dan seksualitas. Jakarta: EGC.

Corwin, E.J. (2009). Buku saku patofisiologi. Jakarta: EGC.

Hendrik, H. (2006). Problema haid (Tinjauan syariat islam dan medis). Solo: Tiga Serangkai.

Huges, W.T., Amstrong, D., Bodey G.P., Brown A.E., Edwards, J.E., \& Feld, R. (2005). Guidlines for the use of antimicrobial agen in neutropenic patient with unexplained fever. Clin Infect Disk, 3, 51-73.

Kusumawati, Y., \& Kurniawati, D. (2011). Pengaruh dismenore terhadap aktivitas pada siswi SMK. Jurnal Kesehatan Olahraga. 
Wiwin Lismidiati : : Pengaruh Self Tapping terhadap Penurunan Level Dysmenorhea

Muller, C., Jacobs, P., \& Barry, L. (2010). Handbook of the neurobiology of serotonin. London: Elsevier.

Potter, P.A., \& Perry, A. (2005). Buku ajar fundamental keperawatan: Konsep, proses, dan praktik (Edisi 4). Jakarta: EGC.

Proverawati, A., \& Misaroh, S. (2009). Menarche menstruasi pertama penuh makna. Yogyakarta: Nuha Medika.
Sinsin, I. (2008). Seri kesehatan ibu dan anak, masa kehamilan dan persalinan. Jakarta: PT.Gramedia.

Sugiyono. (2007). Metode penelitian pedidikan pendekatan kuantitatif, kualitatif, dan $R \& D$. Bandung: Alfabeta.

The Association of Tapping Touch. (2010). Tapping touch, holistic care for body, mind and planet. Retrived from www.tappingtouch. org. 